\title{
Trehalose-incorporated organic-inorganic hybrid nanocomposites produced by thiol-ene photopolymerization
}

\author{
Mitsuhiro Shibata and Shohei Nagashima
}

Thiol-ene photopolymerizations of isocyanurate-based trithiol (S3I)/mercaptopropyl-substituted random-type polysilsesquioxane $(\mathrm{SQ})$, and allyl-etherified trehalose (AxT) with a degree of allylation $x=6$ or 8 , which was prepared by the reaction of $\alpha, \alpha$-D-trehalose and allyl bromide, produced trehalose-incorporated organic-inorganic hybrid nanocomposites (AxT-S3I/SQys) with an SQ content of $y=10$ or 20 (wt\%). All of the photo-cured hybrid films exhibited high transparencies to visible light. Fourier transform infrared spectroscopy (FT-IR) spectral analysis revealed that the thiol-ene photopolymerization proceeded almost to completion for all of the samples, except that some allyl groups remained for A8T-S3I/SQ20. The glass transition temperatures $\left(T_{\mathrm{g}} \mathrm{s}\right)$ and $5 \%$ weight loss temperatures $\left(T_{5} \mathrm{~s}\right)$ of AxT-S3I/SQys increased with increasing $y$ values. Although the $T_{\mathrm{g}}$ of A6T-S3I/ SQy, which had a hydrogen bonding interaction, was higher than that of A8T-S3I/SQy, the A6T-S3I/SQy $T_{5}$ was lower than the A8T-S3I/SQy $T_{5}$, which had a higher crosslinking density. The tensile strengths and moduli of all of the AxT-S3I/SQys, except for A8T-S3I/SQ20, markedly increased with increasing $y$ values.

Polymer Journal (2016) 48, 111-116; doi:10.1038/pj.2015.84; published online 30 September 2015

\section{INTRODUCTION}

Polysilsesquioxanes with the formula $\left(\mathrm{RSiO}_{3 / 2}\right)_{n}$, where $\mathrm{R}$ is an organic substituent, are useful molecular nanobuilding blocks in the formation of organic-inorganic nanocomposites. ${ }^{1,2}$ The structures of polysilsesquioxanes have been reported as random, ladder, cage (polyhedral) and partial cage structures. Polysilsesquioxanes with organic functional groups can react with organic monomers, oligomers and polymers that possess functional groups to produce organic-inorganic hybrid materials. Uniform dispersion of the nanosized siloxane units in the crosslinked hybrid materials can synergistically improve the bulk properties. ${ }^{3-7}$ Photo-curable organic-inorganic hybrid materials have gathered significant attention in recent years as dental, optical and coating materials with excellent transparency, biocompatibility and thermal, mechanical and adhesive properties. ${ }^{8-12}$ It is desirable for the photo-curable multifunctional polysilsesquioxanes to be liquid compounds that have good miscibility with popular photo-curing resins such as acrylate and methacrylate resins. Multifunctional ME-PSQ (methacrylate-substituted random-type polysilsesqlioxane) ${ }^{13-15}$ and octa(meth)acrylated POSS (polyhedral oligomeric silsesquioxane) 16,17 $^{16}$ are prominent examples of efficient photo-curable liquid inorganic polysilsesquioxanes combining with photo-curing resins.

An alternative approach for photo-curable organic-inorganic hybrid materials is using thiol-ene photopolymerization. ${ }^{18-22}$ Thiol-ene photopolymerization has some advantages over the photopolymerization of (meth)acrylates: an inherently rapid reaction rate, reduced oxygen inhibition, the formation of more homogeneous networks and a low polymerization shrinkage. Matsukawa et al..$^{23}$ and Shreck et al. ${ }^{24}$ independently reported hybrid nanocomposites by the thiol-ene photopolymerization of a multifunctional mercaptopropyl-substituted polysilsesquioxane (SQ) prepared from 3-mercaptopropyl trimethoxysilane and triallyl isocyanurate. Luo et al. prepared thiol-ene hybrids from a thiol-substituted POSS and acrylated castor oil (ACO). ${ }^{25}$ Wang et al. ${ }^{26}$ reported photo-cured thiol-ene hybrids from octa(3-mercaptopropyl)-POSS (SH-POSS) and EA-BPA (bisphenol A epoxy acrylate resin). Li et al. ${ }^{27}$ reported thiol-ene hybrids from SH-POSS and octamethacrylated POSS. Their thiol-ene hybrids displayed good transparency and lacked the phase separation of polysilsesquioxanes from prior studies.

Polysaccharide-based resins with high biocompatibility and biodegradability are promising components of biomaterials applicable to tissue engineering and drug delivery system, in addition to environmentally benign coatings. ${ }^{28,29}$ Recently, we reported bio-based polymer networks by the thiol-ene photopolymerizations of allyl-etherified trehaloses (AxTs) with allylation degrees $(x)$ of 6 and 8 with pentaerythritol-based tetrathiol (S4P) or isocyanurate-based trithiol (S3I). ${ }^{30}$ Although the trehalose-incorporated films were transparent, there was considerable room for further improving the thermal and mechanical properties. Hybridizing the trehaloseincorporated network and polysilsesquioxane is a promising method to improve their drawbacks without reducing the biocompatibility. ${ }^{9,31}$ 
To the best of our knowledge, trehalose-incorporated organicinorganic hybrids have never been reported in previous studies. In this study, trehalose-incorporated organic-inorganic hybrid nanocomposites (AxT-S3I/SQ $y$ ) were prepared by the thiol-ene photopolymerizations of $\mathrm{A} x \mathrm{~T}$ ( $x=6$ or 8 ) with a mixture of S3I and SQ with an SQ content of $y=10$ or 20 (wt $\%$ ), and the effects of SQ on the thermal and mechanical properties were investigated.

\section{EXPERIMENTAL PROCEDURE}

\section{Materials}

1,3,5-Tris(3-mercaptobutyryloxyethyl)-1,3,5-triazine-2,4,6(1H,3H,5H)-trione (S3I, trade name: Karenz MT NR1) were kindly provided by Showa Denko K. K. (Tokyo, Japan). A solution of SQ in 1,2-dimethoxyethane (trade name: Compoceran SQ107, concentration of SQ $74.5 \mathrm{wt} \%$, SH equivalent $206 \mathrm{~g} /$ equivalent, viscosity $42 \mathrm{mPa}$ s at $25^{\circ} \mathrm{C}$ ) was kindly supplied from Arakawa Chemical Industries (Osaka, Japan). The chemical structure of S3I and a typical chemical structure of SQ are shown in Figure 1. A photo-initiator, 2-hydroxy1-[4-(2-hydroxyethoxy)phenyl]-2-methyl-1-propanone (Irgacure 2959, melting point (m.p.) $86.5-89.5^{\circ} \mathrm{C}$, UV/VIS absorption peak in methanol: $276 \mathrm{~nm}$ ) was kindly supplied from Ciba Specialty Chemicals K.K. (Tokyo, Japan). A6T and A8T were prepared by reactions of $\alpha, \alpha$-D-trehalose and allyl bromide at the molar ratios of $1 / 6.6$ and $1 / 8.8$ in the presence of pulverized sodium hydroxide in dimethyl sulfoxide (DMSO) according to the previously reported procedure (Figure 2) ${ }^{30}$ The degrees of allylation measured by the ${ }^{1} \mathrm{H}$-NMR method for A6T and A8T were 5.99 and 7.51, respectively. All of the commercially available reagents were used without further purification.

\section{Thiol-ene photopolymerization of AxT, S3I and SQ}

The thiol-ene photopolymerization of AxT ( $x=6$ or 8 ), S3I and SQ at an allyl/ $\mathrm{SH}$ ratio of $1 / 1$ yielded a photo-cured AxT/S3I/SQ hybrid nanocomposite with an SQ content of $y$ wt $\%$ (AxT-S3T/SQ $y, y=10$ or 20). A typical synthetic procedure for A6T-S3I/SQ10 is as follows: a mixture of A6T (1.67 g, 2.87 mmol, $17.2 \mathrm{mmol}$ allyl), S3I ( $2.65 \mathrm{~g}, 4.67 \mathrm{mmol}, 14.0 \mathrm{mmol} \mathrm{SH})$, Compoceran SQ107 (0.67 g, solid content $0.50 \mathrm{~g}, 3.27 \mathrm{mmol} \mathrm{SH})$, Irgacure 2959 (50 mg, $0.223 \mathrm{mmol}$ ) and acetone $(5 \mathrm{ml})$ was stirred for $30 \mathrm{~min}$ to form a homogeneous solution. The solution was poured onto a glass culture dish with a diameter of $95 \mathrm{~mm}$ and was dried at $60^{\circ} \mathrm{C}$ for $3 \mathrm{~h}$. The obtained mixture was photo-irradiated three times for $15 \mathrm{~s}$ at $1 \mathrm{~min}$ intervals to yield photo-cured A6T/S3I/SQ with an SQ content of $10 \mathrm{wt} \%$ (A6T-S3I/SQ10) film (thickness: $\sim 0.5 \mathrm{~mm}$ ). A SPOT-CURE SP-7 ( $250 \mathrm{~W}$ light source, wavelength $240-440 \mathrm{~nm}$, Ushio, Yokohama, Japan) device equipped with a uniform-radiation optical unit was used for UV curing (irradiation distance $200 \mathrm{~mm}$, irradiation intensity $72 \mathrm{~mW} \mathrm{~cm}^{-2}$ ). In a similar manner, A6T-S3I/SQ20 was produced from A6T (1.77 g, $3.04 \mathrm{mmol}, 18.3 \mathrm{mmol}$ allyl), S3I $(2.23 \mathrm{~g}, 3.93 \mathrm{mmol}, 11.8 \mathrm{mmol} \mathrm{SH})$ and Compoceran SQ107 (1.34 g, $1.00 \mathrm{~g} \mathrm{SQ}, 6.55 \mathrm{mmol} \mathrm{SH})$. In addition, A8T-S3I/SQ10 and A8T-S3I/SQ20 were produced from A8T (1.59g, 2.48 mmol, $18.6 \mathrm{mmol}$ allyl and $1.63 \mathrm{~g}, 2.53 \mathrm{mmol}, 19.0 \mathrm{mmol}$ allyl, respectively), S3I $(2.91 \mathrm{~g}, 5.13 \mathrm{mmol}, 15.4 \mathrm{mmol} \mathrm{SH}$ and $2.37 \mathrm{~g}, 4.17 \mathrm{mmol}, 12.5 \mathrm{mmol} \mathrm{SH}$, respectively) and Compoceran SQ107 (0.67 g, $0.50 \mathrm{~g} \mathrm{SQ}, 3.27 \mathrm{mmol} \mathrm{SH}$ and $1.34 \mathrm{~g}, 1.00 \mathrm{~g}$ solid, $6.55 \mathrm{mmol} \mathrm{SH}$, respectively).

As a comparison, photo-cured A6T/S3I (A6T-S3I) and photo-cured A8T/S3I (A8T-S3I) films were similarly prepared from A6T (1.70 g, $2.92 \mathrm{mmol}, 17.5$ mmol allyl) and S3I $(3.30 \mathrm{~g}, 5.81 \mathrm{mmol}, 17.5 \mathrm{mmol} \mathrm{SH})$, and A8T $(1.56 \mathrm{~g}$, $2.42 \mathrm{mmol}, 18.2 \mathrm{mmol}$ allyl) and S3I $(3.44 \mathrm{~g}, 6.06 \mathrm{mmol}, 18.2 \mathrm{mmol} \mathrm{SH})$, respectively.

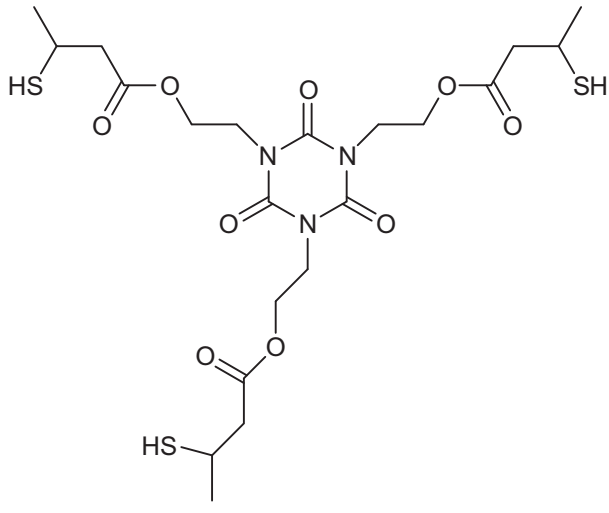

S3I

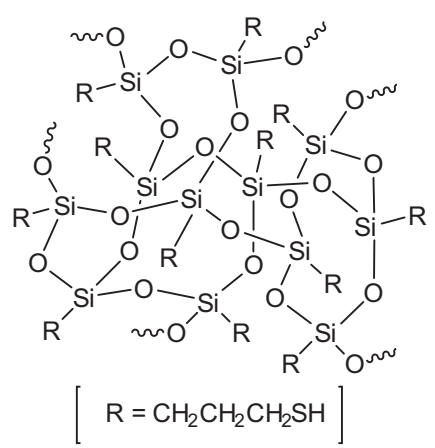

$S Q$

Figure 1 Chemical structures of the S3I and SQ used in this study. S3I, 1,3,5-tris(3-mercaptobutyryloxyethyl)-1,3,5-triazine-2,4,6(1 H,3H,5H)-trione; SQ, mercaptopropyl-substituted polysilsesquioxane.

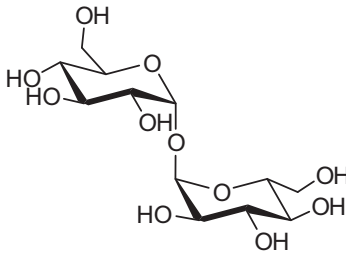

Trehalose

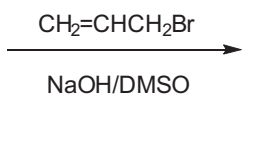

$$
\left[\begin{array}{c}
\mathrm{R}=\mathrm{CH}_{2} \mathrm{CH}=\mathrm{CH}_{2} \text { or } \mathrm{H} \\
\mathrm{CH}_{2} \mathrm{CH}=\mathrm{CH}_{2} / \mathrm{H}=x /(8-x)(x=6 \text { or } 8)
\end{array}\right]
$$$$
\text { AxT }(x=6 \text { or } 8)
$$

Figure 2 Synthetic scheme for A6T and A8T. AxT, allyl-etherified trehalose; DMSO, dimethyl sulfoxide. 


\section{Measurements}

Ultraviolet-visible spectra were recorded on a JASCO V-650 instrument (Tokyo, Japan) over the wavelength range of 400 to $800 \mathrm{~nm}$ using films with thicknesses of $\sim 0.5 \mathrm{~mm}$. Transmission electron microscopy was performed on a H-7650 electron microscope (Hitachi High-Technologies Corporation, Tokyo, Japan) with a $100 \mathrm{kV}$ accelerating voltage. The films were sectioned into $\sim 120 \mathrm{~nm}$ thin sections using an ultramicrotome with a diamond knife and then mounted on 200-mesh copper grids. Fourier transform infrared (FT-IR) spectra were recorded at room temperature in the range from 4000 to $800 \mathrm{~cm}^{-1}$ on a Shimadzu FT-IR 8100 (Kyoto, Japan) by the KBr-pellet or attenuated total reflectance method. The IR spectra were acquired using 50 scans at a resolution of $4 \mathrm{~cm}^{-1}$. Differential scanning calorimetry measurements were performed on a Perkin-Elmer Diamond DSC (Waltham, MA, USA) in a nitrogen atmosphere. To eliminate the thermal history of the samples $(8-12 \mathrm{mg})$, the samples were heated from -100 to $100^{\circ} \mathrm{C}$ at a heating rate of $20^{\circ} \mathrm{C} \mathrm{min}^{-1}$, held at $100^{\circ} \mathrm{C}$ for $3 \mathrm{~min}$, and then cooled to $-100^{\circ} \mathrm{C}$ at a cooling rate of $100^{\circ} \mathrm{C} \mathrm{min}^{-1}$. After the temperature was held at $-100^{\circ} \mathrm{C}$ for $3 \mathrm{~min}$, a second heating scan was performed at a heating rate of $20^{\circ} \mathrm{C} \mathrm{min}-1$ to determine the glass transition temperature $\left(T_{\mathrm{g}}\right)$. The $5 \%$ weight loss temperature $\left(T_{5}\right)$ was measured on a Shimadzu TGA-50 thermogravimetric analyzer at a heating rate of $20^{\circ} \mathrm{C} \mathrm{min}^{-1}$ in a nitrogen atmosphere. Tensile testing of the rectangular plates (length $50 \mathrm{~mm}$, width $10 \mathrm{~mm}$, thickness $0.5 \mathrm{~mm}$ ) was performed at room temperature using an Autograph AG-1 (Shimadzu) based on the standard method for testing the tensile properties of plastics (JIS K7161:1994, ISO527-1). The span length was $25 \mathrm{~mm}$, and the testing speed was $10 \mathrm{~mm} \mathrm{~min}^{-1}$. Five specimens were tested for each set of samples. The mean values were calculated and the standard deviations are displayed as error bars in the graphs.

\section{RESULTS AND DISCUSSION}

\section{Characterization and morphology of $\mathrm{AxT}-\mathrm{S} 3 \mathrm{I} / \mathrm{SQ} y$}

Thiol-ene photopolymerizations of AxTs ( $x=6$ and 8) and S3I/SQ at the allyl/SH ratio of $1 / 1$ produced AxT-S3I/SQ $y$ s $(y=10$ and 20) as transparent and relatively tough films (Figure 3). When the SQ content was $30 \mathrm{wt} \%$, the obtained film was too brittle to be pulled off from the glass culture dish without destroying the film. Figure 4 shows ultraviolet-visible spectra of $0.5-\mathrm{mm}$ thick AxT-S3I/SQ $y$ films. All of the photo-cured nanocomposite films exhibited high transparency to visible light over $400 \mathrm{~nm}$. Deterioration in the transparency with

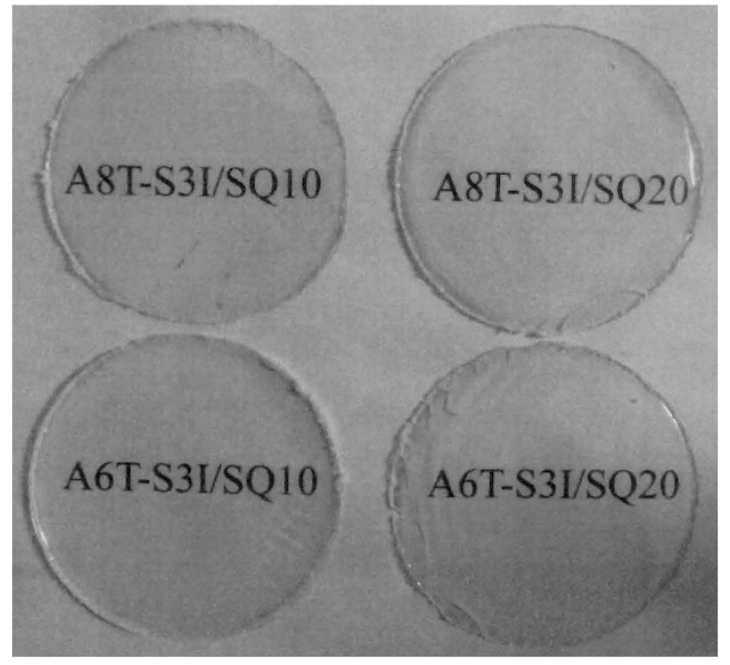

Figure 3 Photographs of the A8T-S3I/SQ10, A8T-S3I/SQ20, A6T-S3I/SQ10 and A6T-S3I/SQ20 films. S3I, 1,3,5-tris(3-mercaptobutyryloxyethyl)-1,3,5triazine-2,4,6(1H,3H,5H)-trione; $S Q$, mercaptopropyl-substituted polysilsesquioxane. A full color version of this figure is available at Polymer Journal online. increasing SQ content up to $20 \mathrm{wt} \%$ was not observed. Figure 5 shows transmission electron microscopy images with a magnification of $\times 100000$ for A6T-S3I/SQ10 and A6T-S3I/SQ20. No particles larger than $10 \mathrm{~nm}$ were observed for either film, indicating that the SQ component is homogeneously incorporated in the polymer network by the thiol-ene reaction. Similar transmission electron microscopy images were also obtained for A8T-S3I/SQ10 and A8T-S3I/SQ20. These results contrasted markedly with our previous result that phase-separated particles with diameters of $\sim 0.1-2 \mathrm{~mm}$ appeared in ACO/ME-PSQ. ${ }^{14}$ The difference in morphology is attributable to the fact that the thiol groups in SQ seldom homopolymerize in the presence of allyl compounds, although the methacrylate groups in ME-PSQ homopolymerize.

Figure 6 shows the FT-IR spectra of all the reactants (S3I, SQ, A6T and A8T). A6T and A8T exhibited absorption bands at $1643 \mathrm{~cm}^{-1}$ and 991 and $918 \mathrm{~cm}^{-1}$, which are characteristic of allyl groups and are ascribed to $\mathrm{C}=\mathrm{C}$ stretching $\left(\nu_{\mathrm{C}=\mathrm{C}}\right)$ and $=\mathrm{C}-\mathrm{H}$ out-of-plane bending $(\gamma=\mathrm{C}-\mathrm{H})$ vibrations, respectively. S3I exhibited strong bands due to ester and amide $\mathrm{C}=\mathrm{O}$ stretching vibrations $\left(\nu_{\mathrm{C}=\mathrm{O}}\right)$ at 1732 and $1686 \mathrm{~cm}^{-1}$, respectively. SQ exhibited strong bands due to the Si-O stretching vibration $\left(\nu_{\mathrm{Si}-\mathrm{O}}\right)$ at $\sim 1000-1080 \mathrm{~cm}^{-1}$. Although the bands of the S-H stretching vibration $\left(\nu_{\mathrm{S}-\mathrm{H}}\right)$ for S3I and SQ were weak, the peaks certainly appeared at 2571 and $2557 \mathrm{~cm}^{-1}$ in the vertically enlarged IR spectra of S3I and SQ, respectively. To check the progress of the thiol-ene polymerization, the allyl $\gamma_{=\mathrm{C}-\mathrm{H}}$ band at $918 \mathrm{~cm}^{-1}$ and the $\nu_{\mathrm{S}-\mathrm{H}}$ band at $\sim 2550-2580 \mathrm{~cm}^{-1}$ were used because the allyl $\nu_{\mathrm{C}=\mathrm{C}}$
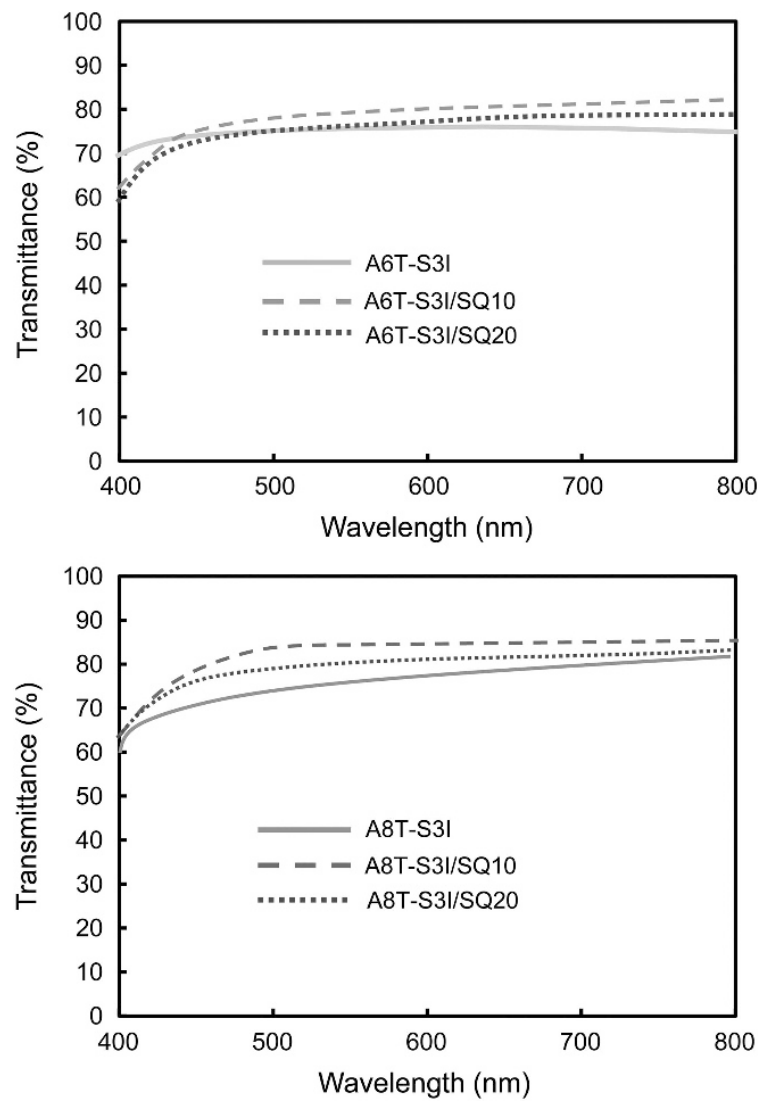

Figure 4 UV-Vis spectra of the 0.5-mm-thick A8T-S3I, A8T-S3I/SQys, A6TS3I and A6T-S3I/SQys films ( $y=10$ and 20). UV-Vis, ultraviolet-visible; S3I, 1,3,5-tris(3-mercaptobutyryloxyethyl)-1,3,5-triazine-2,4,6(1 H,3H,5H)-trione; $\mathrm{SQ}$, mercaptopropyl-substituted polysilsesquioxane. A full color version of this figure is available at Polymer Journal online. 


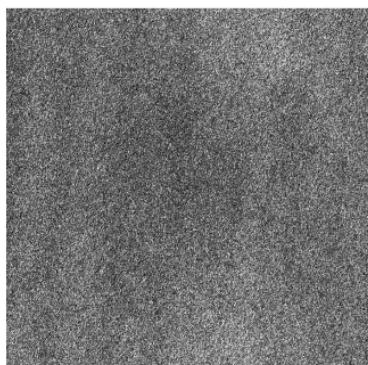

A6T-S3I/SQ10

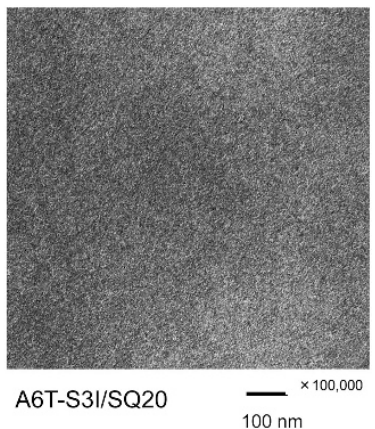

$100 \mathrm{~nm}$

Figure 5 TEM images of A6T-S3I/SQ10 and A6T-S3I/SQ20. S3I, 1,3,5tris(3-mercaptobutyryloxyethyl)-1,3,5-triazine-2,4,6(1H,3H,5H)-trione; $S Q$, mercaptopropyl-substituted polysilsesquioxane; TEM, transmission electron microscopy.

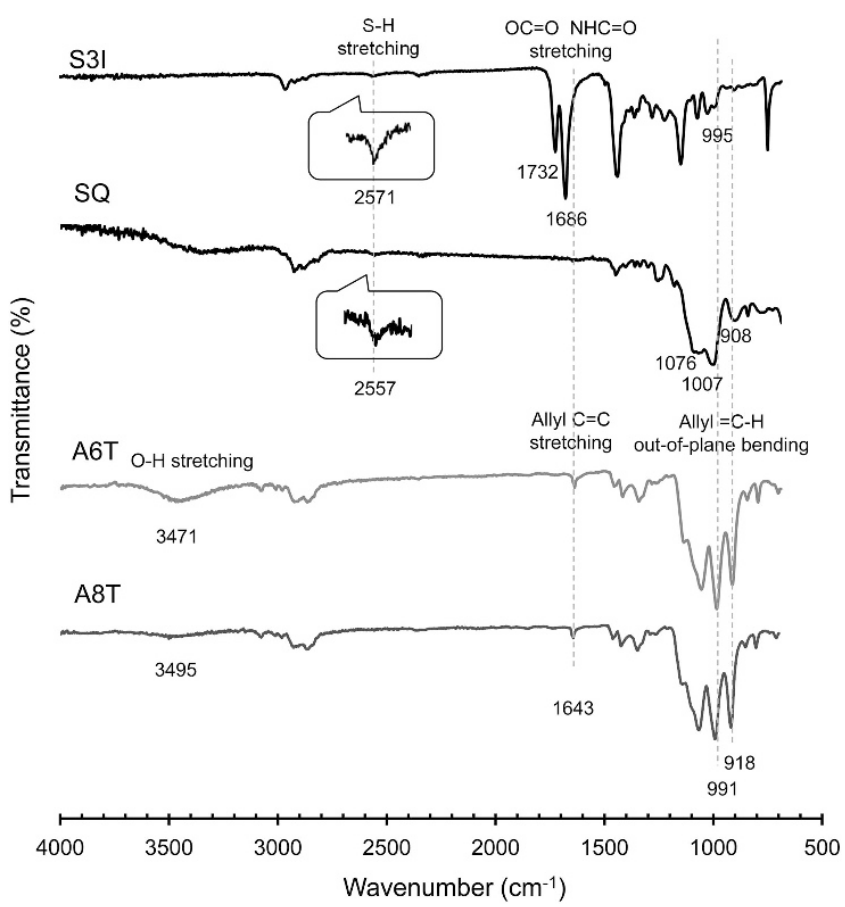

Figure 6 FT-IR spectra of S3I, SQ, A6T and A8T. FT-IR, Fourier transform infrared; S3I, 1,3,5-tris(3-mercaptobutyryloxyethyl)-1,3,5-triazine-2,4,6 $(1 \mathrm{H}, 3 \mathrm{H}, 5 \mathrm{H})$-trione; $\mathrm{SQ}$, mercaptopropyl-substituted polysilsesquioxane. A full color version of this figure is available at Polymer Journal online.

band at $1643 \mathrm{~cm}^{-1}$ overlapped with the amide $\nu_{\mathrm{C}=\mathrm{O}}$ band at 1686 $\mathrm{cm}^{-1}$ of S3I, and the allyl $\gamma_{=\mathrm{C}-\mathrm{H}}$ band at $991 \mathrm{~cm}^{-1}$ overlapped with the $\nu_{\mathrm{Si}-\mathrm{O}}$ band of SQ at $\sim 1000-1080 \mathrm{~cm}^{-1}$ and the band at $995 \mathrm{~cm}^{-1}$ of S3I. However, the thiol-ene conversion could not be quantitatively evaluated, as the allyl $\gamma=\mathrm{C}-\mathrm{H}$ band at $918 \mathrm{~cm}^{-1}$ slightly overlapped with a weak band at $908 \mathrm{~cm}^{-1}$ that appeared in the S3I spectrum.

Figure 7 shows FT-IR spectra for the AxT-S3I/SQ $y$ films. The allyl $\gamma=\mathrm{C}-\mathrm{H}$ band at $918 \mathrm{~cm}^{-1}$ and the $\nu_{\mathrm{S}-\mathrm{H}}$ band at approximately $2550-2580 \mathrm{~cm}^{-1}$ were almost nonexistent for any of the AxT-S3I/ SQ $y$ films except for A8T-S3I/SQ20, indicating that the allyl and thiol groups almost completely reacted to produce hybrid composites. The fact that a weak allyl $\gamma=\mathrm{C}-\mathrm{H}$ band at $918 \mathrm{~cm}^{-1}$ appeared for A8T-S3I/ SQ20 suggests that the thiol-ene reaction is hindered because A8TS3I/SQ20 should produce a congested network with the highest crosslinking density.

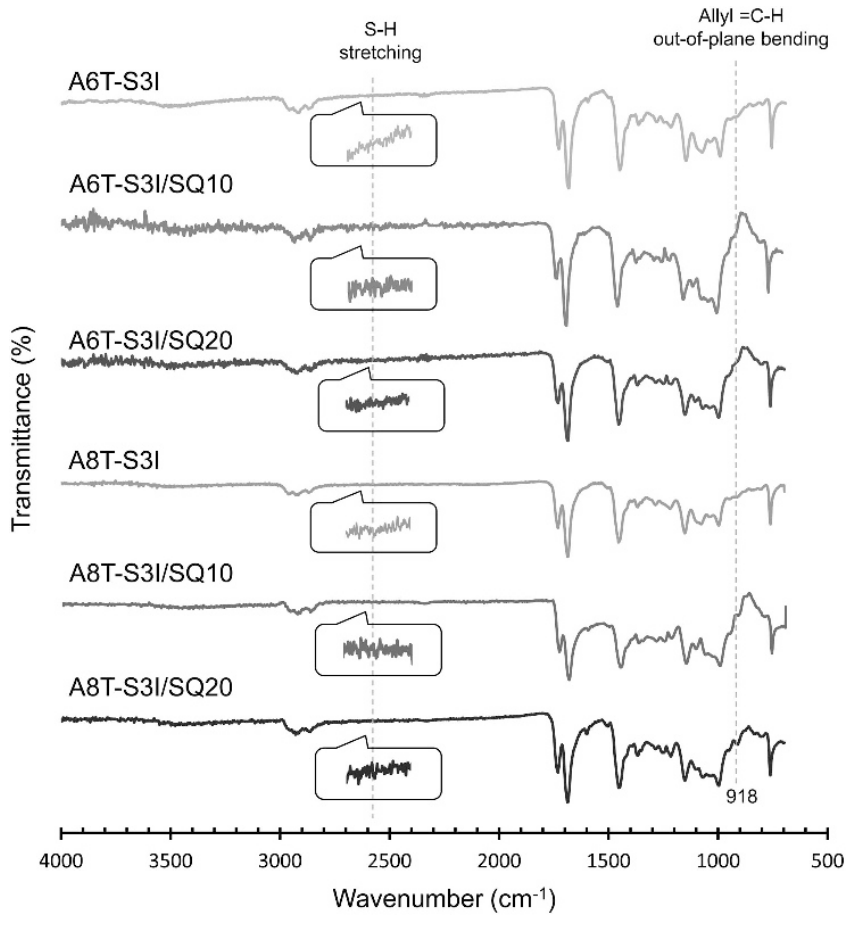

Figure $7 \mathrm{FT}-\mathrm{IR}$ spectra of AxT-S3ls, AxT-S3I/SQ10s and AxT-S3I/SQ20s $(x=6$ and 8). AxT, allyl-etherified trehalose; FT-IR, Fourier transform infrared; S3I, 1,3,5-tris(3-mercaptobutyryloxyethyl)-1,3,5-triazine-2,4,6(1 H, $3 H, 5 H$ )-trione; $S Q$, mercaptopropyl-substituted polysilsesquioxane. A full color version of this figure is available at Polymer Journal online.

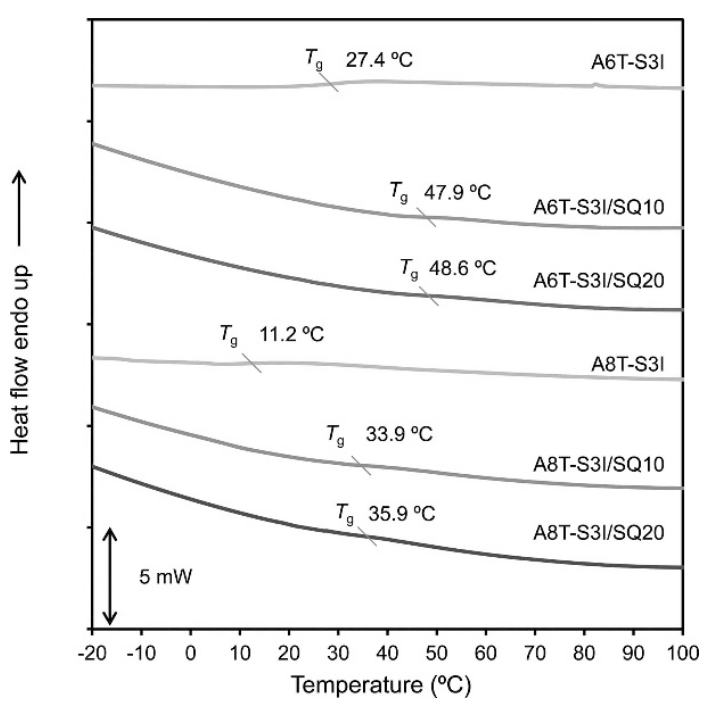

Figure 8 Second-heating DSC curves of AxT-S3ls, AxT-S3I/SQ10s and AxT-S3I/SQ20s ( $x=6$ and 8). AxT, allyl-etherified trehalose; DSC, differential scanning calorimetry; S3I, 1,3,5-tris(3-mercaptobutyryloxyethyl)1,3,5-triazine-2,4,6(1H,3H,5H)-trione; $S Q$, mercaptopropyl-substituted polysilsesquioxane. A full color version of this figure is available at Polymer Journal online.

Thermal and mechanical properties of $\mathrm{AxT}-\mathrm{S} 3 \mathrm{I} / \mathrm{SQ} y$

Figure 8 shows differential scanning calorimetry curves for AxT-S3I/ SQys, A6T-S3I and A8T-S3I. No melting endothermal peak was observed in their differential scanning calorimetry thermograms, 
indicating that all the samples are amorphous. The $T_{\mathrm{g}}\left(27.4^{\circ} \mathrm{C}\right)$ of A6T-S3I was higher than that $\left(11.2^{\circ} \mathrm{C}\right)$ of A8T-S3I. This result may be attributed to the contribution of hydrogen bonding interactions of the residual hydroxy groups of A6T. ${ }^{30}$ A similar trend was observed for the A6T-S3I/SQ $y$ and A8T-S3I/SQ $y$ hybrids. The $T_{\mathrm{g}} \mathrm{s}$ of A6T-S3I/ SQ $y$ and A8T-S3I/SQ $y$ hybrids increased with an increasing $y$ value in agreement with the fact that SQ has a rigid polysilsesquioxane moiety and a higher thiol functionality than S3I does. Notably, the $T_{\mathrm{g}} \mathrm{s}$ increased considerably in this case compared with the previously reported result that the $T_{\mathrm{g}} \mathrm{s}\left(-42\right.$ to $\left.-49^{\circ} \mathrm{C}\right)$ of thiol-ene hybrids derived from ACO and a thiol-substituted POSS (POSS-OA/SH) prepared from a 1:1 mixture of n-octyltriethoxysilane and 3-mercaptopropyl trimethoxysilane were much lower than that $\left(-23.9^{\circ} \mathrm{C}\right)$ of photo-crosslinked ACO.$^{25}$ The lower $T_{\mathrm{g}}$ was reasonably explained by the fact that the average molecular weight between crosslinks $\left(M_{\mathrm{c}}\right)$ of the hybrids using POSS-OA/SH is much higher than that of the crosslinked ACO. Regarding AxT-S3I/SQ $y$, the theoretical weight per thiol equivalent $\left(\mathrm{C}_{3} \mathrm{H}_{7} \mathrm{SSiO}_{1.5}=127.2 \mathrm{~g} \mathrm{~mol}^{-1}\right)$ of SQ is certainly lower than that $\left(\mathrm{C}_{21} \mathrm{H}_{33} \mathrm{~N}_{3} \mathrm{O}_{9} \mathrm{~S}_{3} / 3=189.2 \mathrm{~g} \mathrm{~mol}^{-1}\right)$ of S3I, indicating that an increase in the SQ content leads to a lower $M_{\mathrm{c}}$, consequently resulting in a higher $T_{\mathrm{g}}$. However, the difference $\left(0.7-2.0^{\circ} \mathrm{C}\right)$ of the $T_{\mathrm{g}} \mathrm{s}$ between $\mathrm{A} x \mathrm{~T}-\mathrm{S} 3 \mathrm{I} / \mathrm{SQ} 10$ and AxT-S3I/SQ20 was much smaller than that $\left(20.5-22.7^{\circ} \mathrm{C}\right)$ between $\mathrm{AxT}-\mathrm{S} 3 \mathrm{I}$ and AxT-S3I/SQ10. This result can be explained by the fact that the mercaptopropyl group of SQ is a flexible unit, which reduces the rigidity of the polymer chains. This hypothesis is supported by the previous result that the $T_{\mathrm{g}}\left(87^{\circ} \mathrm{C}\right)$ of an EA-BPA/SH-POSS hybrid with a SH-POSS content of $20 \mathrm{wt} \%$ was lower than that $\left(100^{\circ} \mathrm{C}\right)$ of the corresponding $10 \mathrm{wt} \%$ hybrid. $^{26}$
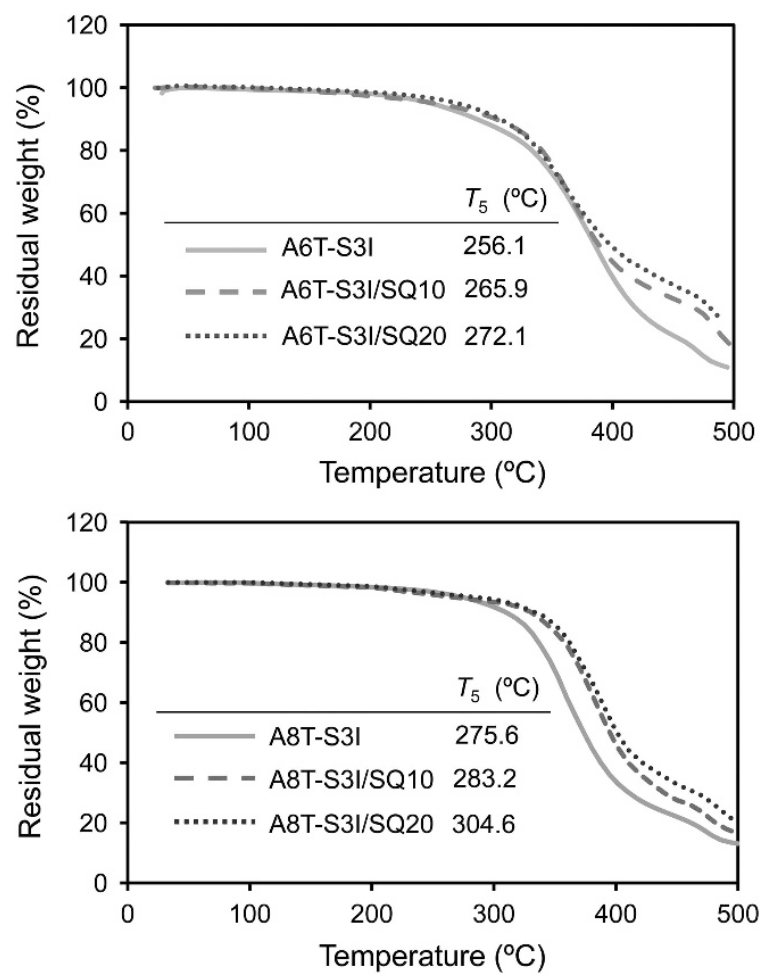

Figure 9 TGA curves of AxT-S3Is, AxT-S3I/SQ10s and AxT-S3I/SQ20s $(x=6$ and 8). AxT, allyl-etherified trehalose; S3I, 1,3,5-tris(3-mercaptobutyryloxyethyl)-1,3,5-triazine-2,4,6(1H,3H,5H)-trione; SQ, mercaptopropylsubstituted polysilsesquioxane; TGA, thermogravimetric analysis. A full color version of this figure is available at Polymer Journal online.
Figure 9 shows thermogravimetric analysis curves for AxT-S3I/ SQ $y$ s, A6T-S3I and A8T-S3I. The $T_{5}$ s of the A6T-S3I/SQ $y$ and A8TS3I/SQ $y$ hybrids increased with increasing $y$ values, in agreement with the fact that SQ has a polysilsesquioxane moiety with excellent thermal resistance. In addition, the heat resistance should be improved by an increase in the crosslinking density with increasing $y$ values because the weight reduction by thermal bond cleavage is suppressed by the presence of crosslinking points. The $T_{5}$ of A8T-S3I/SQ $y$ was higher than that of A6T-S3I/SQ $y$, attributable to the crosslinking density of A8T-S3I/SQ $y$ being higher than that of A6T-S3I/SQ $y$ and the A6Tbased hydroxy-containing sugar units possessing lower heat resistance than the A8T-based sugar units. ${ }^{30}$ The char yields at $500{ }^{\circ} \mathrm{C}$ for the hybrids similarly increased with increasing $y$ values. Considering the previously reported result that the maximal thermal degradation temperature $\left(T_{\mathrm{d} \text {, } \max }=418^{\circ} \mathrm{C}\right)$ of EA-BPA/SH-POSS $20 \mathrm{wt} \%$ hybrid is lower than that $\left(439^{\circ} \mathrm{C}\right)$ of photo-crosslinked EA-BPA, and that the $T_{\mathrm{d} \text {,max }}$ of SH-POSS itself is $380^{\circ} \mathrm{C},{ }^{26} \mathrm{SQ}$ can be an effective modifier for polymers with relatively low heat resistances $\left(<\sim 350^{\circ} \mathrm{C}\right)$.

Figure 10 shows the tensile properties of the photo-cured resins and hybrids at room temperature. The tensile strengths and tensile moduli of the A6T-S3I/SQ $y$ s markedly increased with increasing $y$ values,
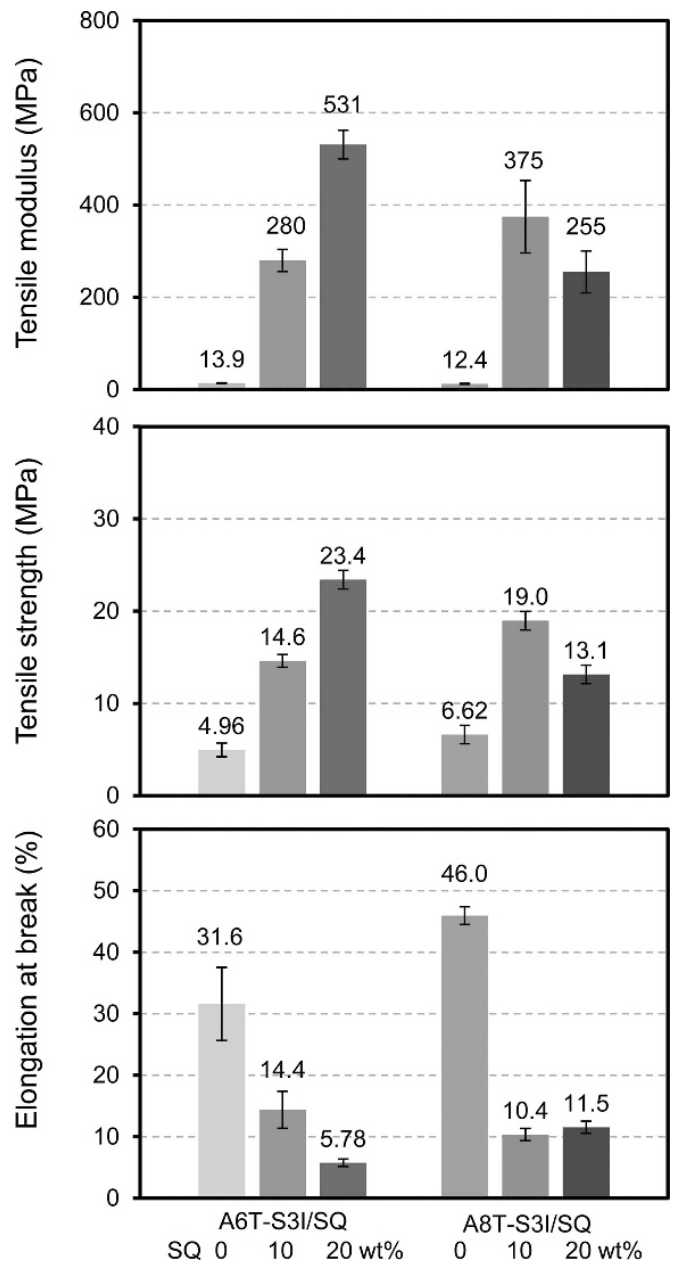

Figure 10 Tensile properties of AxT-S3ls, AxT-S3I/SQ10s and AxT-S3I/ SQ20s ( $x=6$ and 8). AxT, allyl-etherified trehalose; S3I, 1,3,5-tris (3-mercaptobutyryloxyethyl)-1,3,5-triazine-2,4,6(1H,3H,5H)-trione; SQ, mercaptopropyl-substituted polysilsesquioxane. A full color version of this figure is available at Polymer Journal online. 
indicating the reinforcement effect by a rigid polysilsesquioxane moiety in SQ. However, elongations at the breaks of the A6T-S3I/ $\mathrm{SQ} y \mathrm{~s}$ decreased with increasing $y$ values, indicating that the materials became more brittle owing to an increase in the crosslinking density. The tensile strengths and moduli for the A6T-S3I/SQ ys were considerably improved compared with the previously reported result that the flexural strengths and moduli for thiol-ene hybrids based on bisphenol A ethoxylate dimethacrylate, pentaerythritol tetrakis(3-mercaptopropionate) and SQ were modestly increased. ${ }^{24}$ This result can be attributed to the fact that A6T-S3I/SQ10 ( $T_{\mathrm{g}}: 47.9^{\circ} \mathrm{C}$ ) and A6T-S3I/SQ20 $\left(T_{\mathrm{g}}: 48.6^{\circ} \mathrm{C}\right.$ ) are in glassy states at the temperature of tensile testing, $\sim 25^{\circ} \mathrm{C}$, and their tensile properties should be more strongly affected compared with those of A6T-S3I $\left(T_{\mathrm{g}}: 27.4^{\circ} \mathrm{C}\right)$, which is in a glassy/rubbery transition state at $\sim 25^{\circ} \mathrm{C}$. Similarly, the tensile strength and modulus of A8T-S3I/SQ10 were much higher than those of A8T-S3I. However, A8T-S3I/SQ20 displayed a slightly lower tensile strength and modulus than A8T-S3I/SQ10 did. This result can be attributed to the fact that the conversion of A8T-S3I/SQ20 in the thiol-ene reaction is lower than that of A8T-S3I/SQ10, as is obvious from the FT-IR spectral analysis.

\section{CONCLUSIONS}

Thiol-ene photopolymerizations of $\mathrm{AxT}(x=6$ or 8 ) and S3I/SQ produced AxT-S3I/SQ $y$ s $(y=10$ and 20$)$ as transparent films. All the photo-cured hybrid films exhibited high transparencies to visible light. The transmission electron microscopy observation showed no particles larger than $10 \mathrm{~nm}$ for any of the hybrid films. An FT-IR spectral analysis revealed that the thiol-ene photopolymerization proceeded almost to completion for all the samples, except that some allyl groups remained for A8T-S3I/SQ20. The $T_{\mathrm{g}} \mathrm{s}$ and $T_{5} \mathrm{~s}$ of AxT-S3I/SQ $y \mathrm{~s}$ increased with increasing $y$ values. Although the $T_{\mathrm{g}}$ of A6T-S3I/SQ $y$, which had greater hydrogen bonding, was higher than that of A8T-S3I/SQ $y$, the A6T-S3I/SQ $y T_{5}$ was lower than that of A8T-S3I/ $\mathrm{SQ} y$, which had a higher crosslinking density. The tensile strengths and moduli of all the AxT-S3I/SQ $y$ s, except for A8T-S3I/SQ20, increased considerably with increasing $y$ values. SQ was an effective reinforcing nanobuilding block to improve the relatively poor thermal and mechanical properties of bio-based thiol-ene polymer networks without reducing the transparency.

\section{CONFLICT OF INTEREST}

The authors declare no conflict of interest.

\section{ACKNOWLEDGEMENTS}

We gratefully acknowledge financial support from the Chiba Institute of Technology. We thank Dr Naozumi Teramoto and Dr Toshiaki Shimasaki of our department for their helpful suggestions.

1 Abe, Y. \& Gunji, T. Oligo- and polysiloxanes. Prog. Polym. Sci. 29, 149-182 (2004).

2 Baney, R. H., Itoh, M., Sakakibara, A. \& Suzuki, Toshio. T. Silsesquioxanes. Chem. Rev. 95, 1409-1430 (1995).

3 Loy, D. A. \& Shea, K. J. Bridged polysilsesquioxanes. Highly porous hybrid organicinorganic materials. Chem. Rev. 95, 1431-1442 (1995).
4 Lee, A. \& Lichtenhan, J. D. Viscoelastic responses of polyhedral oligosilsesquioxane reinforced epoxy systems. Macromolecules 31, 4970-4974 (1998).

5 Laine, R. M., Choi, J. \& Lee, I. Organic-inorganic nanocomposites with completely defined interfacial interactions. Adv. Mater. 13, 800-803 (2001).

6 Kuo, S.-W. \& Chang, F.-C. POSS related polymer nanocomposites. Prog. Polym. Sci. 36, 1649-1696 (2004).

7 Asuncion, M. Z. \& Laine, R. M. Silsesquioxane barrier materials. Macromolecules 40, 555-562 (2007).

8 Wang, W., Sun, X., Huang, L., Gao, Y., Ban, J., Shen, L. \& Chen, J. Structure-property relationships in hybrid dental nanocomposite resins containing monofunctional and multifunctional polyhedral oligomeric silsesquioxanes. Int. J. Nanomed. 9, 841-852 (2014).

9 Wu, J. \& Mather, P. T. POSS Polymers: physical properties and biomaterials applications. J. Macromol. Sci. Part C Polym. Rev. 49, 25-63 (2009).

10 Lee, B. K., Kim, D.-P., Ryu, J.-H., Park, J., Baek, K.-H. \& Do, L.-M. Poly(ethylene glycol)-functionalized photocurable silsesquioxane as an antibiofouling material for nanostructure-based biomedical applications. Jpn. J. Appl. Phys. 52, 06GG01-1-06G.

11 Bauer, F., Decker, U., Naumov, S. \& Riedel, C. Photoinitiator-free UV curing and matting of acrylate-based nanocomposite coatings: Part 3. Prog. Org. Coat. 77, 1085-1094 (2014)

12 Kozakiewicz, J. Polysiloxaneurethanes:new polymers for potential coating applications. Prog. Org. Coat. 27, 123-131 (1996).

13 Ando, S., Someya, Y., Takahashi, T. \& Shibata, M. Thermal and mechanical properties of photo-cured organic-inorganic hybrid composites of terpene-based acylate resin and methacrylate-substituted polysilsesquioxane. J. Appl. Polym. Sci. 115, 3326-3331 (2010)

14 Shibata, M. \& Obara, S. Photo-cured organic-inorganic hybrid composites of acrylated castor oil and methacrylate-substituted polysilsesquioxane. J. Appl. Polym. Sci. 126, E12-E20 (2012).

15 Ito, M., Shimasaki, T., Teramoto, N. \& Shibata, M. Photo-cured organic-inorganic hybrid composites of methacrylate-terminated 4-arm star-shaped $\varepsilon$-caprolactone oligomer and methacrylate- or thiol-substituted polysilsesquioxane. J. Polym. Res. 21, 507 (2014).

16 Wang, Y., Fengguo Liu, F. \& Xue, X. Morphology and properties of UV-curing epoxy acrylate coatings modified with methacryl-POSS. Prog. Org. Coat. 78, 404-410 (2015).

17 Lin, H.-M., Wu, S.-Y., Chang, F.-C. \& Yen, Y.-C. Photo-polymerization of photocurable resins containing polyhedral oligomeric silsesquioxane methacrylate. Mater. Chem. Phys. 131, 393-399 (2011).

18 Morgan, C. R., Magnotta, F. \& Ketley, A. D. Thiol/ene photocurable polymers. J. Polym. Sci. Polym. Chem. Ed. 15, 627-645 (1977).

19 Hoyle, C. E., Lee, T. Y. \& Roper, T. Thiol-enes: Chemistry of the past with promise for the future. J. Polym. Sci. Part A Polym.Chem. 42, 5301-5338 (2004).

20 Dondoni, A. The emergence of thiol-ene coupling as a click process for materials and bioorganic chemistry. Angew. Chem. Int. Ed. 47, 8995-8997 (2008).

21 Nilsson, C., Simpson, N., Malkoch, M., Johansson, M. \& Malmström, E. Synthesis and thiol-ene photopolymerization of allyl-ether functionalized dendrimers. J. Polym. Sci. Part A Polym. Chem. 46, 1339-1348 (2008)

22 Lowe, A. B. Thiol-ene "click" reactions and recent applications in polymer and materials synthesis. Polym. Chem. 1, 17-36 (2010).

23 Matsukawa, K., Fukada, T., Watase, S. \& Goda, H. Preparation of photo-curable thiolene hybrids and their application for optical materilas. J. Photopolym. Sci. Technol. 23, 115-119 (2010).

24 Schreck, K. M., Leung, D. \& Bowman, C. N. Hybrid prganic/inorganic thiol-ene-based photopolymerized networks. Macromolecules 44, 7520-7529 (2011).

25 Luo, A., Jiang, X., Lina, H. \& Yina, J. Thiol-ene" photo-cured hybrid materials based on POSS and renewable vegetable oil. J. Mater. Chem. 21, 12753-12760 (2011).

26 Wang, X., Wang, X., Song, L., Xing, W., Tang, G. \& Hu, W. Preparation and thermal stability of UV-cured epoxy-based coatings modified with octamercaptopropyl POSS. Thermochim. Acta 568, 130-139 (2013).

$27 \mathrm{Li}$, L., Liang, R., Li, Y., Liu, H. \& Feng, S. Hybrid thiol-ene network nanocomposites based on multi(meth)acrylate POSS. J. Colloid Interface Sci. 406, 30-36 (2013).

28 Shelke, N. B., James, R., Cato T. Laurencin, C. T. \& Kumbar, S. G. Polysaccharide biomaterials for drug delivery and regenerative engineering. Polym. Adv. Technol. 25, 448-460 (2014).

29 Baldwin, A. D. \& Kiick, K. L. Polysaccharide-modified synthetic polymeric biomaterials. Biopolymers 94, 128-140 (2010).

30 Nagashima, S., Shimasaki, T., Teramoto, N. \& Shibata, M. Trehalose-incorporated polymer network by thiol-ene photopolymerization. Polym. J. 46, 728-735 (2014).

31 Punshon, G., Vara, D. S., Sales, K. M., Kidane, A. G., Salacinski, H. J. \& Seifalian, A. M. Interaction between endothelial cells and a poly(carbonate-silsesquioxane-bridge-urea) urethane. Biomaterials 26, 6271-6279 (2005). 